\title{
Uji Coba Pembentukan Sinogram Menggunakan Sensor Tunggal
}

\author{
Verdaus Yogo Saputro ${ }^{1}$, Jodelin Muninggar ${ }^{1}$, Andreas Setiawan ${ }^{1, *}$ \\ ${ }^{1}$ Program Studi Fisika, Fakultas Sains dan Matematika, Universitas Kristen Satya Wacana, \\ Salatiga, Jawa Tengah 50711 \\ *email korespondensi: andreas.setiawan@uksw.edu
}

Received : 12 Desember 2021; Revised : 22 Desember 2021; Accepted : 3 Januari 2022; Published : 7 Januari 2022

\section{ABSTRAK}

Pada proses tomografi diperlukan sinogram sebagai data pembentuknya. Sinogram dalam hal ini akan memberikan informasi intensitas radiasi pada setiap sudut proyeksi radiasi untuk masing-masing sensor. Hasil dari serapan radiasi yang diterima oleh setiap sudut proyeksi akan dibentuk dengan sinogram dan akan mengasilkan citra gambar untuk hasil akhirnya. Pada penelitian ini diajukan gagasan pembentukan sinogram menggunakan sensor tunggal. Sensor yang digunakan pada penelitian ini hanya mampu menerima paparan sumber radiasi pada satu arah. Pada penelitian ini akan dikembangkan metode pemecahan sensor menggunakan kurva distribusi normal. Hal ini bertujuan supaya sensor dapat menerima radiasi dari berbagai arah sehingga intensitas radiasi pada setiap sudut proyeksi radiasi akan diproyeksikan ke dalam sinogram. Algortima yang digunakan adalah membagi sensor menjadi 8 bagian titik serap radiasi. Pembagian sensor ini mengacu pada kurva distribusi normal, sehingga didapatkan 8 selang nilai sensor yaitu -0,05, -0,1,-0,15,-,2, $0,0,2,0,15,0,1$, dan 0,05 terhadap nilai rata-ratanya. Ujicoba dilakukan dengan melakukan penyinaran awal pada sudut $0^{\circ}$ sampai sudut $360^{\circ}$ dengan kenaikan sudut sebesar $5^{\circ}$. Langkah berikutnya dilakukan penyinaran selama 60 detik. Data yang diambil adalah nilai yang diterima sensor pada saat detik ke 60. Hasil pengukuran semua sudut selanjutnya digunakan dalam pembentukan sinogram. Keberhasilan pembentukan sinogram dalam ujicoba ini menjadi langkah awal pembentukan tomografi yang lebih efisien pada tahap selanjutnya.

Kata-kata kunci: sensor; sinogram; sumber radiasi

\section{PENDAHULUAN}

Pemanfaatan zat radioaktif pada saat ini sudah banyak digunakan, diantaranya pada bidang kedokteran nuklir, industri dan bidang penelitian dan pelatihan (Suryaningsih, 2021). Secara global perkembangan zat radioaktif yang digunakan sebagai sumber radiasi sangat pesat termasuk di Indonesia. Sumber radiasi digunakan untuk mendiagnosa atau bisa digunakan sebagai alat untuk terapi penyakit atau kelainan yang ada di dalam tubuh manusia (Kasmudi, 2017). Perkembangan sumber radiasi sudah merambah bidang kedokteran nuklir yaitu digunakan dalam bidang radioterapi. Radioterapi digunakan untuk menyembuhkan penyakit seperti tumor dan kanker (Kasmudi, 2017). Radioterapi dikenal juga dengan istilah brakiterapi (brachyteraphy), berasal dari bahasa Yuniani "brachy" atau jarak pendek. Sensor merupakan bagian pendeteksi dari sumber radiasi. Sensor bekerja dan memberikan hasil serapan radiasi ketika sumber radiasi melakukan penyinaran (Kristiyanti, 2014). Dalam hal ini sensor radiasi berperan sebagai alat untuk merekam berbagai kemungkinan yang terjadi saat melakukan pengobatan atau penyinaran menggunakan sumber radiasi.

Sinogram merupakan bentuk gambar 2D dari penampang suatu objek (Juan dkk., 2021). Sinogram dapat menyajikan satu set proyeksi penampang dalam urutan sudut yang meningkat untuk masing-masing sensornya. Sinogram digunakan dalam proses pembentukan citra gambar tomografi yaitu berasal dari berbagai nilai serapan obyek yang direkam sensor radiasi. Proyeksi sangat berpengaruh terhadap citra gambar yang dihasilkan, semakin banyak proyeksi maka citra gambar yang dihasilkan semakin mendekati dengan kriteria citra gambar yang diinginkan (Catur \& Kusminarto, 2015). Hasil dari penjumlahan proyeksi akan disusun berdasarkann kenaikan tiap sudut pada penyinaran dan dibentuk citra gambar sinogram (Mirul, 2017). Pada sistem umumnya digunakan banyak sensor yang diletakan secara paralel untuk merekam radiasi yang menembus obyek. Untuk sistem seperti ini diperlukan banyak sensor agar sinogram yang terbentuk cukup detil memberikan informasi serapan obyek (Sumariyah dkk., 2009). Untuk penggunaan sensor tunggal akan diperlukan tambahan penggerak tersendiri diluar pergerakan sudut. Hal 
ini selain menambah kerumitan dan biaya juga proses scanning yang berlangsung lebih lama. Jika ini terjadi pada pasien tentu akan merugikan karena menambah jumlah paparan radiasi pengion yang berpotensi membahayakan kesehatan. Berdasar pada hal tersebut pada penelitian ini diajukan gagasan pengembangan algoritma untuk memecah data dari sensor tunggal. Pemecahan data menggunakan pembobotan kurva distribusi normal. Dengan demikian proses pengukuran cukup dilakukan 1 kali pada setiap sudut sehingga selain lebih murah juga memerlukan waktu ekspose radiasi yang lebih singkat. Sejauh studi pustaka yang dilakukan, model pembobotan sensor sudah dilakukan pada riset yang lain, namun belum ditemukan aplikasinya secara khusus pada sensor radiasi (Maani dkk., 2019; Marcel, dkk., 2012).

\section{EKSPERIMEN}

\section{Alat dan Bahan}

Pada penelitian ini alat dan bahan yang digunakan diperlihatkan pada Gambar 1 yaitu terdiri dari sumber radiasi (sinar gamma Cs-137), obyek (kertas kotak) dan detektor radiasi (sensor). Dalam penelitian ini sumber radiasi yang tersedia di laboratorium memiliki energi radiasi yang rendah sehingga sensor tidak mampu membaca perubahan tingkat radiasi pada obyek yang terlalu tebal. Dengan alasan tersebut maka digunakan material kertas yang tipis dan kosong agar level transimisi radiasi masih dapat diukur oleh sensor. Sedangkan untuk posisi obyek, sesuai dengan hukum Beer Lambert maka yang menentukan intesitas serapan radiasi hanyalah ketebalan obyek, sedangkan posisinya tidak berpengaruh. Dengan demikian jika obyek diposisikan vertikal maupun horizontal maka yang menentukan nilai serapan hanyalah lintasan yang dilalui berkas radiasi yang menuju sensor. Dalam hal ini sensor yang digunakan adalah sensor Geiger Muller Counter Br-6b. Kelebihan sensor ini adalah bersifat portabel sehingga mudah dibawa dan bisa melakukan pengukuran radiasi dimana saja. Selain itu sensor ini dapat menerima serapan radiasi dari sumber radiasi gamma, beta maupun sinar x (Amazon, 2019).

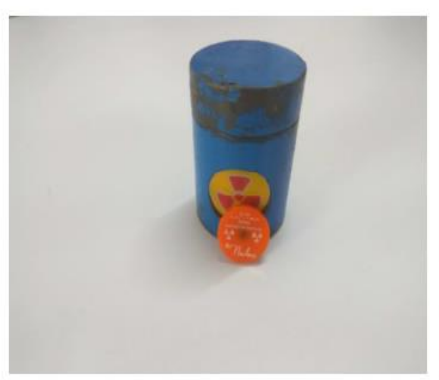

(a)

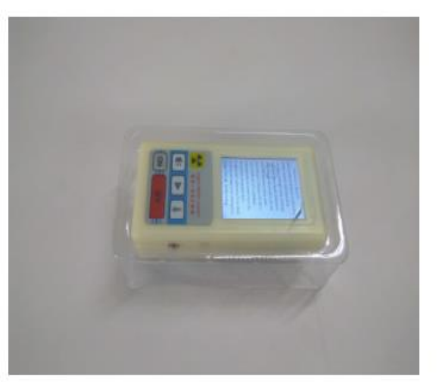

(b)

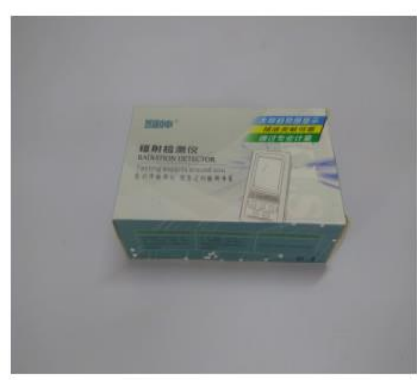

(c)

Gambar 1. Sumber radiasi (sinar gamma Cs-137) (a), sensor (b), dan obyek (kertas kotak) (c).

\section{Instrumen}

Data yang digunakan dalam penelitian ini adalah pengukuran serapan sumber gamma (Cs-137) pada obyek kertas yang diterima oleh sensor radiasi. Posisi antara sumber radiasi dan sensor berjarak 41 $\mathrm{cm}$ dimana posisi obyek diletakan diantara sumber radiasi dan sensor dalam posisi sejajar, seperti diperlihatkan pada Gambar 2.

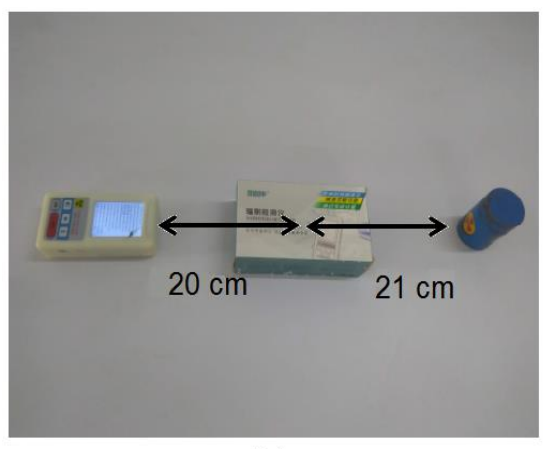

(a)

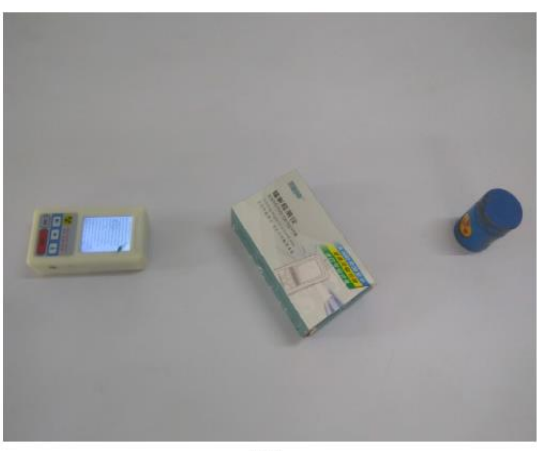

(b)

Gambar 2. Posisi sudut penyinaran saat awal (a) dan setelah diputar (b), perubahan sudut dilakukan mulai dari $0^{\circ}$ hingga $360^{\circ}$ dengan kenaikan setiap $5^{\circ}$. 


\section{Prosedur Kerja}

Pada penelitian ini posisi awal obyek dalam proses pengambilan data berada pada sudut $0^{\circ}$ atau sejajar dengan sumber radiasi dan sensor, kemudian dilakukan perhitungan waktu selama 60 detik. Untuk mendapat nilai serapan radiasi, awal posisi sudut obyek adalah $0^{\circ}$ atau sejajar antara sumber radiasi dan sensor (Kusminarto dkk., 2000). Pada detik ke 60 angka yang ditampilkan pada sensor akan dicatat sebagai serapan radiasi pada posisi $0^{\circ}$. Hal tersebut dilakukan dengan rentang perbedaan 5 derajat $\left(0^{\circ}, 5^{\circ}, 15^{\circ}\right.$ dan seterusnya) sampai sudut $360^{\circ}$ atau kembali sejajar antara sumber dan sensor radiasi.

Setelah pengukuran dilakukan dilanjutkan dengan pembobotan sesuai kurva distribusi normal (Gambar 3). Dalam hal ini dipilih delapan distribusi nilai yang akan dibentuk sehingga seluruh kurva dibagi menjadi 8 selang (Wicaksono, 2013).

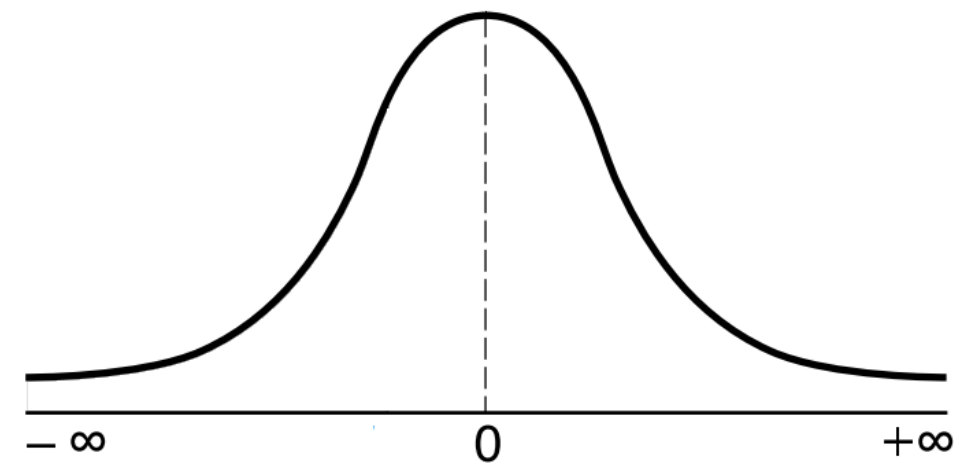

Gambar 3. Kurva distribusi normal.

\section{HASIL DAN DISKUSI}

\section{Hasil penyinaran awal}

Sebelum melakukan penyinaran terlebih dahulu mengukur nilai radiasi lingkungan yang ada disekitar tempat penyinaran. Hal ini bertujuan untuk mengetahui apakah ada sesuatu yang dapat mempengaruhi nilai saat penyinaran, seperti benda elektronik atau yang lainnya. Setelah semua diperiksa maka proses penyinaran dapat dilakukan. Tabel 1 menunjukkan hasil proses penyinaran dengan perbedaan sudut tiap $5^{\circ}$ yang menghasilkan 73 data.

Tabel 1. Data pengukuran sensor tunggal sesuai sudut masing-masing

\begin{tabular}{cc|cc|cc|cc|cc}
\hline $\begin{array}{c}\text { Sudut } \\
\text { (derajat) }\end{array}$ & $\begin{array}{c}\text { Data X } \\
\text { (uSv/h) }\end{array}$ & $\begin{array}{c}\text { Sudut } \\
\text { (derajat) }\end{array}$ & $\begin{array}{c}\text { Data X } \\
\text { (uSv/h) }\end{array}$ & $\begin{array}{c}\text { Sudut } \\
\text { (deraja } \\
\text { t) }\end{array}$ & $\begin{array}{c}\text { Data X } \\
\text { (uSv/h) }\end{array}$ & $\begin{array}{c}\text { Sudut } \\
\text { (derajat) }\end{array}$ & $\begin{array}{c}\text { Data X } \\
\text { (uSv/h) }\end{array}$ & $\begin{array}{c}\text { Sudut } \\
\text { (derajat) }\end{array}$ & $\begin{array}{c}\text { Data X } \\
\text { (uSv/h) }\end{array}$ \\
\hline 0 & 43,42 & 75 & 84,11 & 150 & 99,99 & 225 & 34,05 & 300 & 72,45 \\
5 & 38,25 & 80 & 71,16 & 155 & 99,99 & 230 & 36,21 & 305 & 73,3 \\
10 & 57,75 & 85 & 90,27 & 160 & 99,99 & 235 & 36,15 & 310 & 24,36 \\
15 & 41,16 & 90 & 74,29 & 165 & 85,21 & 240 & 34,49 & 315 & 21,53 \\
20 & 93,3 & 95 & 85,07 & 170 & 81,19 & 245 & 42,1 & 320 & 29,57 \\
25 & 59,5 & 100 & 71,57 & 175 & 65,38 & 250 & 45,36 & 325 & 26,65 \\
30 & 67 & 105 & 90 & 180 & 53,61 & 255 & 47,99 & 330 & 29,14 \\
35 & 57,78 & 110 & 97,94 & 185 & 43,15 & 260 & 55,88 & 335 & 19,52 \\
40 & 79,9 & 115 & 76,64 & 190 & 48,49 & 265 & 55,74 & 340 & 37,09 \\
45 & 90,32 & 120 & 93,15 & 195 & 48,73 & 270 & 46,56 & 345 & 37,69 \\
50 & 69,4 & 125 & 88,33 & 200 & 28,65 & 275 & 52,9 & 350 & 36,54 \\
55 & 76,38 & 130 & 72,64 & 205 & 35,43 & 280 & 53,9 & 355 & 42,83 \\
60 & 12,39 & 135 & 59,97 & 210 & 13,5 & 285 & 51,39 & 360 & 59,26 \\
65 & 77,89 & 140 & 91,2 & 215 & 31,91 & 290 & 63,25 & & \\
70 & 67,51 & 145 & 99,45 & 220 & 28,91 & 295 & 56,8 & & \\
\hline
\end{tabular}

Tabel 1 merupakan tabel data penyinaran yang memberikan nilai transmisi radiasi pada obyek. Selanjutnya kurva distribusi normal dibagi menjadi delapan area seperti diperlihatkan pada Gambar 4. 
Masing-masing area kemudian digunakan sebagai bobot pembagian untuk pengukuran radiasi tunggal Tabel 1. Rentang $-0,05$ hingga $+0,05$ dipilih karena integral kurvanya sudah melebihi $95 \%$ dari total luas dibawah kurva sehingga pengaruh bobot diluar rentang ini menjadi tidak signifikan lagi.

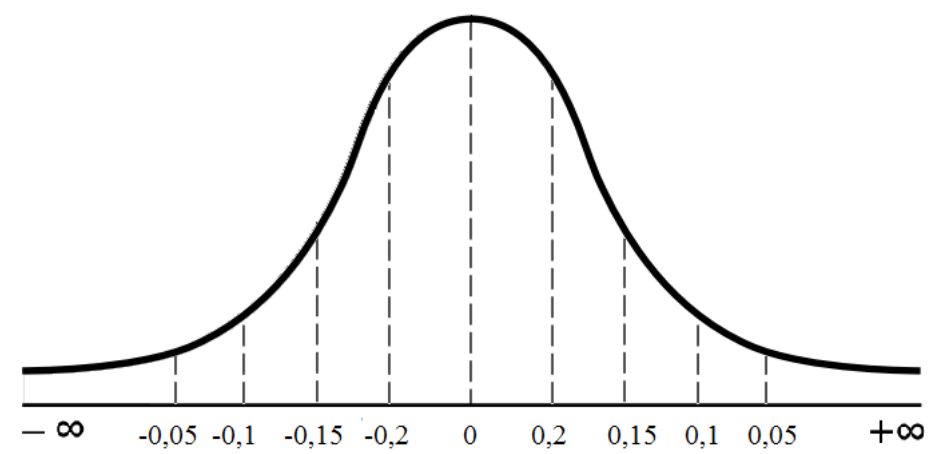

Gambar 4. Hasil pembagian sensor menjadi 8 bagian sesuai sebaran kurva normal.

\section{Pembagian sensor menjadi 8 bagian}

Setelah bobot sensor dihitung maka selanjutnya data pengukuran dari Tabel 1 dapat dipecah menjadi 8 nilai terdistribusi untuk setiap sudutnya. Berikut merupakan contoh tingkat serapan radiasi yang diterima tiap pada setiap nilai terdistribusi. Pada sudut $0^{\circ}$ data pengukuran radiasi yang dihasilkan adalah $43,42 \mu \mathrm{Sv} / \mathrm{h}$, sehingga :

1. $0,2 \times 43,42=8,684 \mu \mathrm{Sv} / \mathrm{h}$

2. $0,15 \times 43,42=6,513 \mu \mathrm{Sv} / \mathrm{h}$

3. $0,1 \times 43,42=4,342 \mu \mathrm{Sv} / \mathrm{h}$

4. $0,05 \times 43,42=2,171 \mu \mathrm{Sv} / \mathrm{h}$

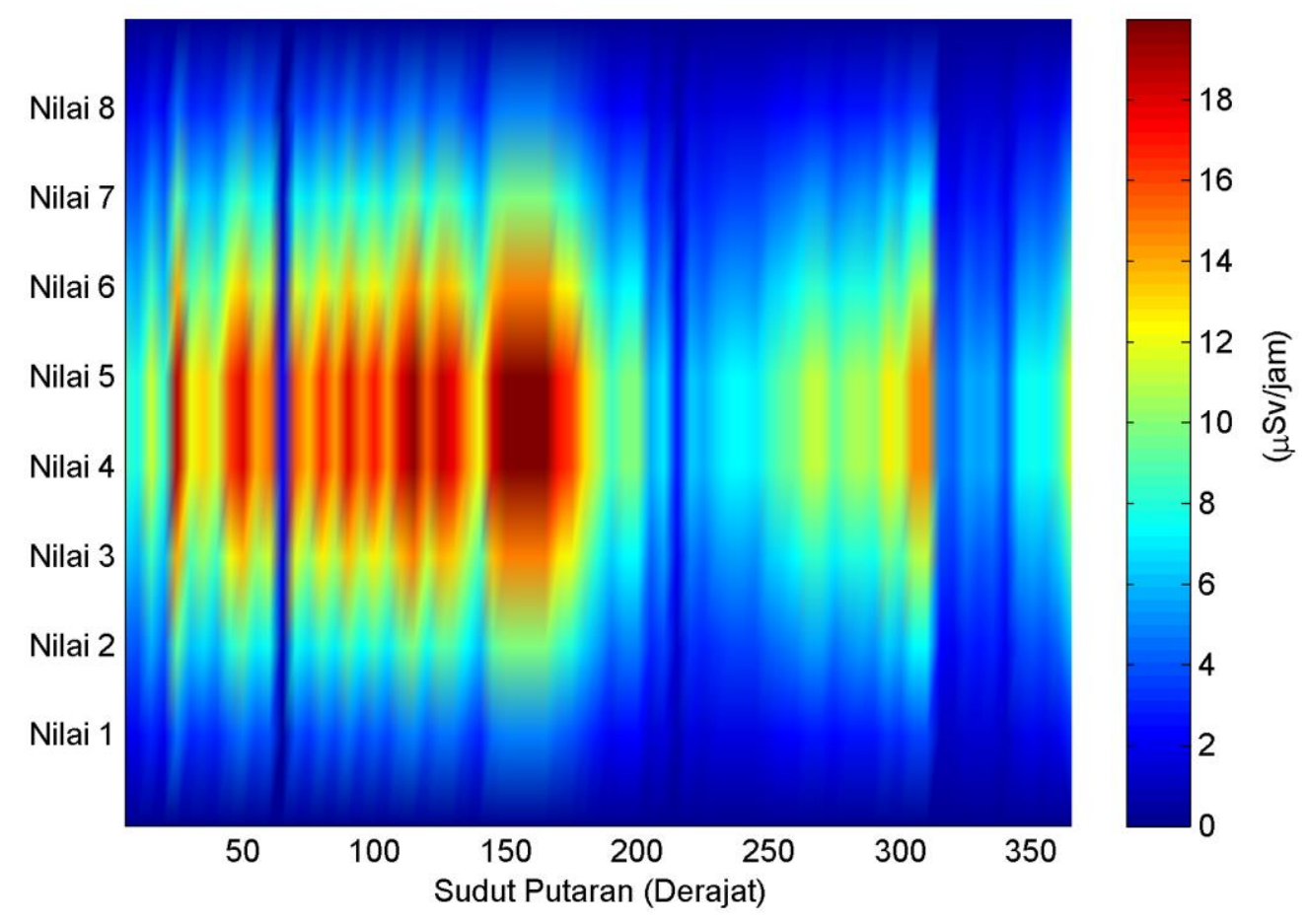

Gambar 5. Citra sinogram yang dibentuk dari pemecahan pengukuran sensor tunggal menjadi 8 sensor menggunakan pembobotan kurva normal.

Total penjumlahan dari setiap sensor diatas adalah $21,71 \mu \mathrm{Sv} / \mathrm{h}$. Jjika melihat hasil pembagian sensor berdasarkan kurva distribusi normal terbagi menjadi 2, yaitu daerah + dan - . Tetapi dalam hal ini tidak berpengaruh terhadap total nilai serapan radiasi yang diterima pada sudut $0^{\circ}$. Totalnya tetap sama karena terdiri dari 2 daerah sehingga $21,71 \times 2=43,42 \mu \mathrm{Sv} / \mathrm{h}$. Dengan nilai ini serapan radiasi yang didapatkan pada sudut $0^{\circ}$ tetap sama dengan hasil penyinaran awal pada Tabel 1. Perhitungan ini selanjutnya dilakukan untuk seluruh posisi sudut pengukuran yang ada pada Tabel 1. Jika setiap data pengukuran dipecah menjadi 8 nilai terdistribusi maka data akhir yang didapatkan berjumlah $8 \times 73$ data 
untuk keseluruhan sudut. Selanjutnya sejumlah data ini disusun menjadi sinogram seperti diperlihatkan pada Gambar 5.

Dari Gambar 5 dapat dilihat bahwa metode yang dikembangkan mampu membentuk kurva sinogram menggunakan sensor tunggal. Terlihat bahwa fluktuasi kurva memperlihatkan keteraturan proses sinusoidal. Hal ini menjadi indikasi awal bahwa terjadi proses distribusi pengukuran sinogram seperti pada umumnya. Meskipun demikian masih perlu dilakukan verifikasi lebih lanjut menggunakan algoritma tomografi untuk melihat obyek yang akan dihasilkan dari proses transformasi baliknya. Menggunakan transformasi balik Radon, hasil kurva sinogram digunakan untuk melakukan rekonstruksi tomografi obyek dengan hasil ditampilkan pada Gambar 6. Dari hasil citra tomografi ini terlihat semacam bentuk persegi seperti obyek yang digunakan. Dengan demikian secara sederhana dapat diperlihatkan bahwa kurva sinogram yang dikembangkan dengan metode ini telah mampu merepresentasikan kembali gambar 2D dari obyek, meskipun masih belum sempurna.

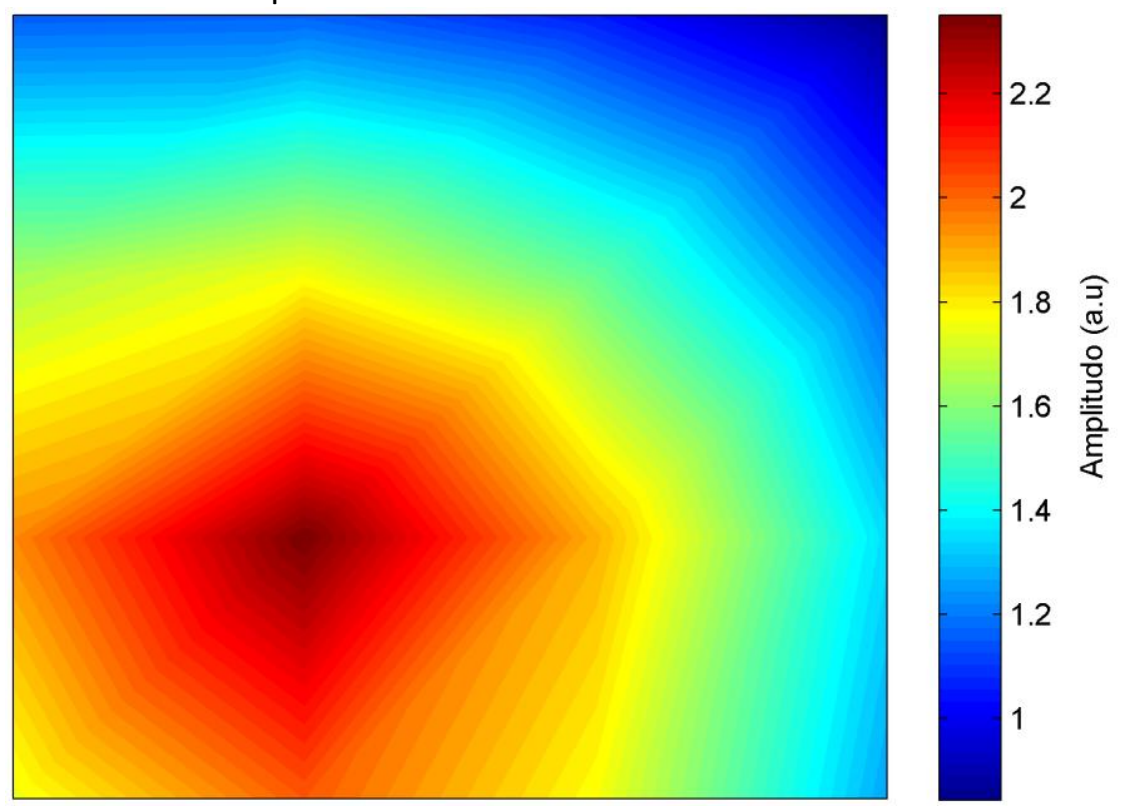

Gambar 6. Hasil transformasi balik Radon sebagai ujicoba pembentukan tomografi menggunakan data sinogram yang dikembangkan. Meskipun belum sempurna namun terlihat bentuk dasar obyek persegi telah muncul pada citranya.

\section{KESIMPULAN}

Berdasarkan hasil analisis dan pembahasan maka dapat disimpulkan bahwa hasil penyinaran sumber radiasi dengan dengan membagi menjadi 8 nilai terdistribusi berhasil dilakukan. Dalam uji ini pembobotan sensor dibagi menjadi 8 bagian berdasarkan kurva distribusi normal, yaitu -0,05, -0,1, -0,15, $0,2,0,0,2,0,15,0,1,0,05$. Selanjutnya optimasi dapat dilakukan dengan melakukan modifikasi pada kurva distribusinya sesuai dengan karakteristik sensor yang digunakan. Demikian juga pembagian area tidaklah harus selalu linear namun dapat sesuai bentuk sensornya. Ujicoba transformasi balik sinogram telah mampu memperlihatkan bentuk tomografi obyek meskipun belum sempurna. Hasil ini menjadi tahap awal untuk kajian berikutnya guna mendapatkan metode tomografi yang lebih efektif.

\section{DAFTAR PUSTAKA}

Amazon. (2019, Agustus 9). Br-6 Radioactivity Detector Portable Geiger Counters Detectable Species Beta Gamma X-ray. Retrieved from https://www.amazon.com/Radioactivity-Detector-Portable-countersdetectable/dp/B07WCDZBY4

Catur, E.W., \& Kusminarto. (2015). Algoritma Interpolasi pada Data Sinogram untuk Rekontruksi Tomografi dari Proyeksi Cacah Terbatas. UGM. Yogyakarta.

Juan, Y.M., Laura, A.S.L., Ali, W., \& Andreas. Ch.L. (2021). Rancangan Bangun Prototype Sistem Akuisisi Citra Digital Untuk Proses Tomografi. Universitas Nusa Cendana. Kupang. 
Kasmudin. (2017). Analisis Karakteristik Beberapa Sumber Radiasi Gamma Untuk Brakiterapi dengan Menggunakan MCPN6. Badan Teknologi Nuklir Nasional.

Kristiyanti, E.K. (2014). Analisis Dosis Radiasi pada Kolam Iradiator Gamma 2 MCi Menggunakan MCNP. Majalah Prima, Volume 11, Nomor 2. PRPNBATA. Puspiptek Serpong.

Kusminarto., Agung, B.S.U., \& Gede, B.S. (2000). Pengukuran Sensitivitas Tomografi Komputer Transmisi: Studi Eksperimen Pendahuluan. Fisika UGM. Yogyakarta.

Maani, G.J., Jaime, V.M., \& Gamini, D. (2019). Samping-based Incremental Information Gathering with Application to Robotic Exploration and Environmental Monitoring. The International Journal of Robotics Research, Volume 38, Nomor 6. 658-685.

Marcel, R., \& Werner, B. (2012). Reconstructing Power Cables From LIDAR Data Using Eigenvector Streamlines of the Point Distribution Tensor Field. Conference: WSCG2012-20-th International Conference in Central Europe on Computer Graphics, Visualization and Computer Vision. June 2528. Plzen. Czech Republic.

Mirul, Ka. (2017, Juni 18). Prinsip Tomografi (Integral Garis). Retrieved from http://ksience.blogspot.com/2017/06/prinsip-tomografi-integral-garis.html

Sumariyah., Zainul, M., \& Evi, S. (2009). Rekontruksi Citra Tomografi Sinar-X Flouresens 2D Berbasis Teknik Radiografi Digital Menggunakan Bahasa Pemrograman Matlab 7.1. Fisika UNDIP. Tembalang.

Suryaningsih, I. (2021). Analisis Pola Sebaran Dosis Radiasi Sumber 137Cs Di Ruang Penyinaran Iradiator BPFK Surabaya. Institut Teknologi Sepuluh November. Surabaya.

Wicaksono. P. (2013, Maret 14). Mengenal Distribusi Normal dan Cara Membaca Tabel Distribusi Normal. Retrieved from http://analisis-statistika.blogspot.com/2013/03/mengenal-distribusi-normal-dancara.html 